\title{
Knowledge, Attitudes, and Practices (KAP) Regarding Physical Activity among Healthcare Professionals (HCPs) in Suva, Fiji
}

\author{
Keresi Rokorua Bako ${ }^{1}$, Masoud Mohammadnezhad ${ }^{2}$ \& Sabiha Khan ${ }^{2}$ \\ ${ }^{1}$ Department of Public Health, University of Otago, Wellington, New Zealand \\ ${ }^{2}$ School of Public Health and Primary Care, Fiji National University, Suva, Fiji Islands \\ Correspondence: Masoud Mohammadnezhad, Associate Professor of Public Health (Health Promotion), School of \\ Public Health and Primary Care, Fiji National University, Suva, Fiji Islands. Tel: 679-972-6127.
}

\author{
Received: Febary 12, 2021 Accepted: April 17, 2021 Online Published: May 8, 2021 \\ doi:10.5539/gjhs.v13n6p91 URL: https://doi.org/10.5539/gjhs.v13n6p91
}

\begin{abstract}
Background: More than $60 \%$ of the world's population is not physically active. Physical inactivity affects all sectors of the population including among healthcare professionals (HCPs). The objective of this study was to determine the level of knowledge, attitudes and practices (KAP) regarding the concept, benefits and health consequences of physical activity (PA) among HCPs in Suva, Fiji.
\end{abstract}

Methods: This quantitative, cross-sectional study was conducted among HCPs in Suva, Fiji between 1 July 2017 and 22 September 2017. All available HCPs including doctors, nurses and paramedics who were willing to take part in the study were included. A validated self-administered questionnaire was used to assess the level of KAP regarding PA. Data was analysed with Statistical Package for the Social Sciences (SPSS) 25.

Results: 126 HCPs participated in this study with the majority being female $(73.8 \%)$, in the age range of $33-42$ years $(47.6 \%)$, married $(81.7 \%)$, from the nursing profession $(54.0 \%)$ and within $0-5$ years of experience $(27.0 \%)$. The results showed that most of the participants (96.8\%) had a high level of knowledge, positive attitudes (100\%) and good practice $(95 \%)$ regarding PA.

Conclusion: Although the study participants had high levels of knowledge and positive attitudes towards PA, it is important to promote their practice. Using tailored behavioural change theories that focus on perceived benefits and barriers of PA may help decision-makers to promote PA in the workplace and among HCPs in Fiji.

Keywords: physical activity, healthcare professions, knowledge, attitudes, practice, Fiji

\section{Introduction}

Physical activity (PA) is any movement of the body that requires energy expenditure (Westerterp, 2013; WHO 2012). PA includes activities which involve body movement such as playing, working, active transportation, doing house chores and recreational activities (Kesaniemi \& Danforth, 2001). PA should be of moderate or vigorous intensity in order to have health benefits (Caspersen \& Powell, 2000) which includes mobility and incidental activity integrated into daily activity (WHO, 2016).

The World Health Organization (WHO) reported that more than $60 \%$ of the world's population are not physically active enough to induce health benefits due to lifestyle choices (WHO, 2012). PA and sedentary time appear to be potentially modifiable health behaviours that can reduce risks for morbidity and premature mortality resulting from various chronic diseases (Williams et al., 2010). In most parts of the world, non-communicable diseases (NCDs) have become a major health challenge, partially because of rapid changes in lifestyle, leading to reduced PA and changing diets and an increase in sedentary behaviour. This trend is present in all societies, rich and poor, developed and developing. Low levels of PA can increase the risk factors for NCDs including coronary heart disease, cancer, type 2 diabetes mellitus, obesity, osteoporosis, depression and anxiety (WHO, 2012). PA has been found to reduce the risk of developing chronic diseases by $50 \%$ (Craig et al., 2003). A lack of PA is a major contributing factor to Fiji's current NCD crisis. People do not fully realise the positive impact PA can have on managing health issues such as high blood pressure, obesity, reducing cholesterol, as well as maintaining a healthy weight (Carter et al., 2011).

PA increases life expectancy and the overall quality of life (Motl \& McAuley, 2010). According to WHO, 150 
minutes of moderate intensity PA or 75 minutes of vigorous activity per week are recommended to achieve health benefits (Olufemi et al., 2015). Regular PA is also highly beneficial in communities and for economies in terms of reduced health care costs, increased productivity, better performance in employees, lower worker absenteeism and turnover, increased productivity and increased participation in sports and recreational activities (Woolf, 2012; Andersen, 2000).

It has been noted from previous studies (Olufemi \& Ebenezer, 2015; Andersen \& Schnohr, 2000) that people who get into any form of employment have different levels of and perceptions towards PA. Employment has created some factors that lead to barriers to PA, such as unfavourable working conditions, longer working hours and stress at work that may influence the lifestyle of the workers and lead to a reduction of PA and increase of leisure time activities (Vandelanotte \& Short, 2015). In contrast, Hébert (2012) and Burgoyne (2008) report that exposure to work activities with more learning opportunities and a high capacity for decisions on the task carried out can increase the likelihood of increased PA in leisure time. The workplace can potentially provide opportunities to promote PA, by introducing healthy settings to integrate PA in to the daily programmes of work places. Healthcare professionals (HCPs) play a unique and important role in motivating and assisting patients' healthy behaviour changes, including PA promotion. HCPs are less likely to counsel patients on improved PA if their own health habits are poor. Previous reports (Lahti, 2010; Jamil, 2016; Lindwall, 2014) suggest that active HCPs are more likely to provide better, more credible and motivating preventive counselling to their patients (Michael, 2015; Ribera, 2005; Olifemi, 2015; Skaal, 2011).

There is lack of evidence regarding the knowledge, attitudes and practices (KAP) regarding PA among HCPs in Fiji. Thus, the aim of the study was to determine the level of KAP regarding the concept, benefits and health consequences PA among the HCPs in Fiji. This study sets out to establish descriptive baseline data for PA promotion in Fiji's general practices, and to explore the experiences of HCPs in promoting PA in their day-to-day clinical practices and professional lives.

\section{Methodology}

\subsection{Study Design and Sample}

This quantitative descriptive study was conducted amongst HCPs in all of the Suva subdivision health care facilities. There are seven health care facilities in the subdivision. These healthcare facilities are Lami Health Centre, Raiwaqa Health Centre, Nuffield Health Centre, Suva Health Office, Samabula Health Centre, Valelevu Health Centre and Makoi Health Centre. The study was conducted between 1 July 2017 and 22 September 2017. The Suva subdivision, located in Fiji's Central Division, is the most highly populated in Fiji. All available HCPs, including medical officers (doctors), nurses, and paramedics who were willing to take part in the study were included. Overall, 126 who met the study criteria participated in this study.

\subsection{Data Collection Tool}

A self-administered questionnaire with close-ended questions was used in this study. The questionnaire covered questions related to KAP. The questionnaire was divided into two sections, with section A containing general information on participants' sociodemographic classification, with section B measuring the KAP level of the participants. The KAP level was further divided into three parts. Part 1 measured the knowledge level, part 2 measured the attitude level and part 3 measured the practice level of the participants. For the knowledge-related questions, the participants were asked 18 questions with three possible responses as "correct (2)", "I do not know (1)", and "incorrect (0)". The minimum and maximum scores for the knowledge-related questions were 0 to 36 . Those who scored $0-18$ were considered as having a "low level" of knowledge, $19-24$ as "medium level" and 25 -36 as a "high level" of knowledge. For attitude-related questions, there were 11 questions with the response of "completely agree (5)", "agree (4)", "no idea (3)", "disagree (2), and "completely disagree (1)". The participants were categorised as having a "high level" of attitudes if the score was between 38 and 55, and a "medium level" of attitudes with the score of 29 and 37, and a "low level" of attitude with the score of 1 and 28. There were eight questions relating to practice and responses were either low level of practice $(0-8)$ or good level of practice $(9-$ 16) towards PA.

The KAP questionnaire was developed by reviewing the literature and using similar questionnaires that have been used earlier (Médecins, 2011). Face validity was carried out with five participants who met the inclusion criteria. They were given the questionnaire to assess whether it was legible, clear, simple, easy, and understandable. These people were not included in the final analysis, and they were not further classified based on their demographic characteristics apart from gender. For content validity, three experts were given the questionnaire to decide whether the content met the objectives of the study. 


\subsection{Study Procedure}

The participants were given the freedom to fill the questionnaire at their own pace, although the participants were requested to fill the questionnaires while they were free from clinical activities. The participants were advised that the information sheet and the consent sheets were both enclosed in the envelope which they needed to read carefully before answering the questionnaire. An attempt was also made to collect the filled questionnaire on the same day of issue at the end of the working day. Some of the participants preferred to take the questionnaires home to fill them in during their free time and collection was done via the nursing sister-in-charge who called the researcher to collect the filled questionnaires. Some questionnaires were collected on the second day, while others the day after. A period of one week was provided to the participants to complete the questionnaire. During the week, the main researcher visited the health centres daily to pick up the filled questionnaires from the participants and some were given to the researcher by the sister-in-charge of the health care facility. Data collection was done in an anonymous manner where the participants were not required to include their names and the questionnaires were sealed in an envelope once completed and given to the person in charge, for the researcher to collect the questionnaires.

\subsection{Data Management and Analysis}

All information from the questionnaires was inserted in a Microsoft Excel data sheet for cleaning and coding and a data dictionary was designed. Afterwards, data were analysed using SPSS, version 25. Descriptive statistics were used initially to demonstrate the baseline sociodemographic characteristics from section A of the questionnaire. The frequency of responses to the KAP questions was expressed in total and percentages.

\subsection{Ethical Considerations}

Ethical approval for this study was obtained from the Fiji National University, College Health Research Ethics Committee (CHREC) and the Fiji National Health Research Ethics and Review Committee (FNHRERC) at the Ministry of Health, Fiji.

The participants were given a written consent form with the information sheet detailing the purpose of the study, and indicated their voluntary participation by signing the consent form.

\section{Results}

126 HCPs participated in this study with the majority being female $(73.8 \%)$, in the age range of $33-42$ years (47.6\%), married (81.7\%), from the nursing profession $(54.0 \%)$ and within $0-5$ years of experience $(27.0 \%)$. The results showed that most of the participants $(96.8 \%)$ had a high level of knowledge, positive attitudes $(100 \%)$ and good practices $(95 \%)$ regarding PA.

On the socioeconomic level, in terms of income level fortnightly, most of the participants (46\%) had an average income of 500 to 1000 Fijian Dollars (FJD) per fortnight. Finally, looking at the ethnicity, the iTaukei (67.5\%) was the largest ethnicity group. Table 1 below describes the sociodemographic characteristics of the study participants.

Table 1. Frequency of participants based on their demographic characteristic $(n=126)$

\begin{tabular}{llcc}
\hline Demographic Characteristics & Categories & Frequency & Percentage \\
\hline \multirow{2}{*}{ Gender } & Male & 33 & 26.2 \\
& Female & 93 & 73.8 \\
\hline \multirow{2}{*}{ Age (year) } & $<32$ & 47 & 37.30 \\
& $33-42$ & 60 & 47.60 \\
\hline \multirow{2}{*}{ Marital status } & $\geq 43$ & 19 & 15.10 \\
\hline \multirow{3}{*}{ Number of children } & Married & 103 & 81.7 \\
& Single & 23 & 18.3 \\
\hline \multirow{2}{*}{ Occupation } & No children & 32 & 25.2 \\
& $1-2$ & 51 & 40.4 \\
\hline
\end{tabular}




\begin{tabular}{llrc}
\hline & Para-medicals & 8 & 6.3 \\
& Other & 21 & 16.7 \\
\hline \multirow{3}{*}{ Working experience (year) } & $0-5$ & 34 & 27.0 \\
& $6-10$ & 33 & 26.2 \\
& $11-15$ & 28 & 22.2 \\
& $16-20$ & 19 & 15.1 \\
& $\geq 21$ & 12 & 9.5 \\
\hline \multirow{3}{*}{ Fortnightly income (FJD) } & $<\$ 500$ & 7 & 5.6 \\
& $\$ 500-\$ 1000$ & 58 & 46.0 \\
& $\$ 1001-\$ 1500$ & 17 & 13.5 \\
& $\$ 1501-\$ 2,000$ & 19 & 15.1 \\
Ethnicity & $>\$ 2001$ & 25 & 19.8 \\
\hline \multirow{2}{*}{ Religion } & iTaukei & 85 & 67.5 \\
& Fijian of Indian Descent & 36 & 28.6 \\
\hline & Others & 5 & 4 \\
\hline
\end{tabular}

The Table 2 below shows the frequencies of the responses and indicates that $96.8 \%$ of respondents understood that PA can decrease obesity and chances of developing Type II diabetes, while $91.3 \%$ were aware that high blood pressure can be reduced by PA. The majority, $90.5 \%$ of respondents, knew that performing PA only on the weekend is not enough to achieve health benefits. Results indicated that $85.7 \%$ of respondents knew that it is necessary to undertake PA at least four to five days a week to receive health benefits, and $87.3 \%$ knew they needed to do PA for at least 30 minutes per day.

Most of respondents $(89.7 \%)$ knew stretching as an aerobic exercise. The majority of them $(92.9 \%)$ knew that a benefit of regular PA is to reduce your risk of a heart attack and manage weight better.

Most of the respondents (95.2\%) chose the correct answer when they were asked if increasing PA has the potential to improve health by significantly reducing the prevalence of chronic disease and lifestyle disease. Of the participants, $92.9 \%$ knew that poor diet and low levels of PA can result in increasing NCDs and obesity, and 93.7\% of them knew PA is key to preventing and controling NCDs such as diabetes and its complications. Nearly all participants $(96 \%)$ were aware that PA can promote the rate of heartbeat and breathing.

Amongst respondents, $80.2 \%$ knew to strengthen the heart and lung function by doing PA daily is useful, and it should be at least 30 minutes to one hour on each occasion (86.5\%). Additionally, $87.3 \%$ of respondents knew that doing some endurance sports, such as marathons, may damage their bones and body; however, $96.8 \%$ of them knew the benefit of doing PA regularly.

The findings indicate that most of the subjects $(96.8 \%)$ knew the definition of PA, and the majority (98.4\%) knew that PA is the best method to reduce weight. 
Table 2. Frequency of responses on knowledge related questions $(n=126)$

\begin{tabular}{|c|c|c|c|}
\hline Knowledge Questions & $\begin{array}{l}\text { Correct } \\
\text { n (\%) }\end{array}$ & $\begin{array}{l}\text { I don't know } \\
\text { n (\%) }\end{array}$ & $\begin{array}{l}\text { Incorrect } \\
\text { n (\%) }\end{array}$ \\
\hline $\begin{array}{l}\text { Physical activity is anybody activity that enhances and maintains physical fitness } \\
\text { and overall health and wellness. }\end{array}$ & $122(96.8)$ & $2(1.6)$ & $2(1.6)$ \\
\hline Physical activity is the best method to reduce weight. & $124(98.4)$ & $0(0)$ & $2(1.6)$ \\
\hline Physical activity can decrease obesity and chances of developing Type II diabetes. & $122(96.8)$ & $3(2.4)$ & $1(0.8)$ \\
\hline High blood pressure can be reduced by physical activity. & $115(91.3)$ & $8(6.3)$ & $3(2.4)$ \\
\hline $\begin{array}{l}\text { Performing physical activity only on weekends is not enough to achieve health } \\
\text { benefits. }\end{array}$ & $114(90.5)$ & $7(5.6)$ & $5(4.0)$ \\
\hline $\begin{array}{l}\text { Is } 4-5 \text { days a week the minimum number a person must be physically active in } \\
\text { order to receive any health benefit? }\end{array}$ & $108(85.7)$ & $7(5.6)$ & $11(8.7)$ \\
\hline $\begin{array}{l}\text { Is } 30 \text { minutes the minimum length of time one needs to be physically active } \\
\text { throughout a typical day in order to achieve a health benefit? }\end{array}$ & $110(87.3)$ & $3(2.4)$ & $13(10.3)$ \\
\hline Is "stretching" an example of aerobic exercise? & $113(89.7)$ & $6(4.8)$ & $7(5.6)$ \\
\hline $\begin{array}{l}\text { Benefits of regular physical activity are to reduce your risk of a heart attack and } \\
\text { manage your weight better. }\end{array}$ & $117(92.9)$ & $5(4.0)$ & $4(3.2)$ \\
\hline $\begin{array}{l}\text { Increasing physical activity has the potential to improve health by significantly } \\
\text { reducing the prevalence of chronic disease and lifestyle disease. }\end{array}$ & $120(95.2)$ & $2(1.6)$ & $4(3.2)$ \\
\hline $\begin{array}{l}\text { One cause of this NCD epidemic is the rapid increase in obesity, which is largely } \\
\text { due to poor diets and low levels of physical activity. }\end{array}$ & $121(96)$ & $0(0)$ & $5(4)$ \\
\hline $\begin{array}{l}\text { The implementation of physical activity is a preventative measure for the prevention } \\
\text { and control of NCDs. }\end{array}$ & $117(92.9)$ & $4(3.2)$ & $5(4.0)$ \\
\hline $\begin{array}{l}\text { Regular physical activity helps you to control your diabetes and reduce developing } \\
\text { complications. }\end{array}$ & $118(93.7)$ & $5(4.0)$ & $3(2.4)$ \\
\hline Your heart rate or breathing increases when you do physical activity. & $121(96.0)$ & $1(0.8)$ & $4(3.2)$ \\
\hline A person should do physical activity every day to strengthen the heart and lungs. & $101(80.2)$ & $8(6.3)$ & $17(13.5)$ \\
\hline $\begin{array}{l}30 \text { minutes to } 1 \text { hour performing physical activity is needed on each occasion to } \\
\text { strengthen the heart and lungs. }\end{array}$ & $109(86.5)$ & $8(6.3)$ & $9(7.1)$ \\
\hline $\begin{array}{l}\text { Endurance sports such as marathon running can sometimes cause fractures in bones } \\
\text { and the body. }\end{array}$ & $110(87.3)$ & $3(2.4)$ & $13(10.3)$ \\
\hline Physical activity performed regularly is beneficial for a long time. & $122(96.8)$ & $2(1.6)$ & $2(1.6)$ \\
\hline
\end{tabular}

As Table 3 below reveals, the majority of the participants $(67.7 \%)$ related that being physically active was enjoyable and they felt comfortable being physically active (65.4\%). More than two-thirds of them (78\%) strongly believed that doing PA frequently was good for their health and most $(81.1 \%)$ described that they give PA high priority among other activities. The majority of the participants $(75.6 \%)$ strongly indicated that they were interested in doing exercise today and in the future and $76.4 \%$ believed strongly that PA improved their physical health. Two-thirds (64.6\%) of them believed that PA provided good opportunities to develop social contacts. More than two-thirds of respondents $(69.3 \%)$ strongly believed that PA helped them to have more control over their eating behaviours. The majority of participants $(78.8 \%)$ strongly believed that PA needs to be included in the health care setting programme and $76.4 \%$ of them strongly believed that obesity is not an indicator of good health. Over half of the respondents (59.1\%) strongly believed that learning about the relationship between PA and health is important for their health. 
Table 3. Frequency of responses on attitude related questions of PA $(n=126)$

\begin{tabular}{|c|c|c|c|c|c|}
\hline Items & $\begin{array}{l}\text { Completely } \\
\text { agree }\end{array}$ & Agree & No idea & Disagree & $\begin{array}{l}\text { Completely } \\
\text { disagree }\end{array}$ \\
\hline Being physically active is enjoyable & $86(67.7)$ & $38(29.9)$ & $0(0)$ & $2(1.6)$ & $0(0)$ \\
\hline It feels comfortable doing physical activities & $83(65.4)$ & $40(31.5)$ & $0(0)$ & $3(2.4)$ & $0(0)$ \\
\hline $\begin{array}{l}\text { I believe that doing physical activity frequently is } \\
\text { good for my health }\end{array}$ & $99(78.0)$ & $27(21.3)$ & $0(0)$ & $0(0)$ & $0(0)$ \\
\hline $\begin{array}{l}\text { I love to give physical activity high priority among } \\
\text { other activities }\end{array}$ & $103(81.1)$ & $23(18.1)$ & $0(0)$ & $0(0)$ & $0(0)$ \\
\hline $\begin{array}{l}\text { I am very interested in doing exercise today and in } \\
\text { the future }\end{array}$ & $96(75.6)$ & $29(22.8)$ & $0(0)$ & $1(0.8)$ & $0(0)$ \\
\hline Physical activity improves my physical health & $97(76.4)$ & $29(22.8)$ & $0(0)$ & $.0(0)$ & $0(0)$ \\
\hline $\begin{array}{l}\text { Physical activity provides good opportunities for } \\
\text { developing social contacts }\end{array}$ & $82(64.6)$ & $39(30.7)$ & $2(1.6)$ & $3(2.4)$ & $0(0)$ \\
\hline $\begin{array}{l}\text { Physical activity helps me to have more control } \\
\text { over my eating behaviours }\end{array}$ & $88(69.3)$ & $33(26.0)$ & $3(2.4)$ & $2(1.6)$ & $0(0)$ \\
\hline $\begin{array}{l}\text { I think physical activity needs to be included in the } \\
\text { health care setting programme }\end{array}$ & $100(78.7)$ & $22(17.3)$ & $1(0.8)$ & $1(0.8)$ & $2(1.6)$ \\
\hline Obesity is not an indicator of good health & $97(76.4)$ & $21(16.5)$ & $2(1.6)$ & $1(0.8)$ & $5(3.9)$ \\
\hline $\begin{array}{l}\text { Learning about the relationship between physical } \\
\text { activity and health is important for my health }\end{array}$ & $75(59.1)$ & $51(40.2)$ & $0(0)$ & $.0(0)$ & $0(0)$ \\
\hline
\end{tabular}

The frequency of participants' reported practice of PA showed that the majority of participants $(81.7 \%)$ do PA and only $14.3 \%$ always do PA. Most of participants (86.5\%) do one to four hours of physical activity per week and only $4.8 \%$ do PA more than four hours per week. The results also revealed that two-thirds of participants (59.5\%) do PA of between six and 30 minutes per day and $31 \%$ do it for more than 30 minutes per day. Mild activity such as walking or going shopping was the main activity during free time (73.8\%), while only $3.2 \%$ choose to do intensive activity during their free time. The majority of participants (79.4\%) spend less than three hours per day watching $\mathrm{TV}$ or working on the computer, while $20 \%$ spend more than three hours per day on these activities. Similarly, the majority (83.3\%) watch TV or a DVD for less than three hours per day when they are at home and only $17 \%$ spend more than three hours per day doing these activities, while the amount of time spent on the computer or laptop was very high among participants $(84.9 \%)$ on weekends. The majority of them $(87.3 \%)$ spend less than three hours per day playing games or using a mobile phone (Table 4).

Table 4. Frequency of responses on practice related questions $(n=126)$

\begin{tabular}{lrr}
\hline Questions & Frequency & Percent \\
\hline How often do you do physical activity (for example: rugby, soccer, netball, dancing, swimming...)? & & \\
Never & 5 & 4.0 \\
Sometimes & 103 & 81.7 \\
Always & 18 & 14.3 \\
\hline How many hours do you practice physical activity (for example: rugby, soccer, netball, dancing, & & \\
swimming...)? & 11 & \\
Never & 109 & 86.7 \\
$1-4$ h/week & 6 & 4.8 \\
\hline 4 h/week & 6 & \\
\hline
\end{tabular}


How long do you do physical activity for (for example: rugby, soccer, netball, dancing, swimming ...)?

$<5 \mathrm{~min} /$ day

$6-30 \mathrm{~min} /$ day

$>30 \mathrm{~min} /$ day

What do you do during your free time?

Sedentary activity (i.e., watching TV)

Mild activity (i.e., shopping/walking)

Intensive activity (practicing a sport)

93

How many hours do you spend on the computer or watching TV per day (on weekdays)?

$<3$ hrs

$100 \quad 79.4$

$3-5 \mathrm{hrs}$

$>6 \mathrm{hrs}$

6

4.8

How many hours do you watch TV or DVD movies at home per day?

$<3$ hrs

$3-5 \mathrm{hrs}$

$>6 \mathrm{hrs}$

How many hours per day on weekends do you usually spend on the computer or laptop away from work?

$<3$ hrs

$3-5 \mathrm{hrs}$

$>6 \mathrm{hrs}$

How many hours per day you usually spend playing video games on mobile phones, tablets etc.?

$<3 \mathrm{hrs} /$ day

$3-6$ hrs/day

$>6 \mathrm{hrs} /$ day

As Table 5 demonstrates, most of the participants (96.8\%) had a high level of knowledge and only $3.2 \%$ had moderate knowledge of PA. In relation to attitude, it was also noted that all the participants $(100 \%)$ were categorised as having a high level of attitude towards PA.

Table 5. Distribution of response by level of knowledge, attitudes and practices $(n=126)$

\begin{tabular}{lcc}
\hline Variables & Frequency & Percentage \\
\hline Knowledge level & 122 & 96.8 \\
High $(25-36)$ & 4 & 3.2 \\
Medium $(19-24)$ & 0 & 0 \\
Low $(0-18)$ & 126 & 100 \\
\hline Attitude level & 0 & 0 \\
High $(38-55)$ & 0 & 0 \\
Medium $(29-37)$ & 120 & 95.5 \\
Low $(1-28)$ & 6 & 4.5 \\
\hline Practice level & & \\
Good practice $(9-18)$ & & \\
Bad practice $(0-8)$ & & \\
\hline
\end{tabular}


As Table 6 shows, the mean knowledge score was $33.65( \pm 3.272)$, which shows that participants have a very high level of knowledge regarding PA. The mean score for attitude was $51.54( \pm 2.175)$, which shows that participants also have high level of attitude (positive attitude) towards PA. The mean practice score was $11.92( \pm 2.639)$, which shows that the participants have generally low level of practice towards PA.

Table 6. Overall mean score of participants' knowledge, attitudes, and practices

\begin{tabular}{lcccc}
\hline & Frequency $(\mathrm{n})$ & Minimum & Maximum & Mean $( \pm$ SD) \\
\hline Knowledge & 126 & 22 & 36 & $33.65( \pm 3.272)$ \\
Attitude & 126 & 42 & 55 & $51.54( \pm 2.175)$ \\
Practice & 126 & 4 & 16 & $11.92( \pm 2.639)$ \\
\hline
\end{tabular}

The results show that there was a non-significant positive relationship between knowledge and attitudes $(\mathrm{r}=0.049)$. Similarly, there was a non-significant positive relationship between knowledge and practices $(r=0.119, \mathrm{p}=0.186)$. There was a non-significant negative relationship between attitudes and practices $(r=-0.002, p=0.984)$ (Table 7).

Table 7. Relationship between knowledge, attitudes and practices

\begin{tabular}{llcc}
\hline Variables & Frequency & r Pearson & p-value \\
\hline Knowledge vs attitude & 126 & 0.049 & 0.585 \\
Knowledge vs practices & 126 & 0.119 & 0.186 \\
Attitudes vs practices & 126 & -0.002 & 0.984 \\
\hline
\end{tabular}

\section{Discussion}

This study aimed to identify the level of KAP regarding PA among HCPs in Fiji. A determination of the level of PA amongst HCPs managing patients presenting with various lifestyle-related conditions is most pertinent, and the levels of physical activity undertaken by HCPs are associated with their counselling behaviour. Overall, this study found that participants had high levels of KAP towards PA.

HCPs should continue to reinforce the benefits of PA in all health promotion venues. On the same note, $96.8 \%$ of participants had high level of knowledge while only $3.2 \%$ had a moderate level of knowledge. The data clearly shows that the majority of the participants were well versed with the parameters of knowledge pertaining to the benefits of PA. The mean knowledge score was 33.65 ( $\mathrm{SD} \pm 3.272$ ), which shows that participants had very high levels of knowledge concerning PA. Although the study participants had a high level of knowledge regarding PA, they had low knowledge when they were asked about "the time needed to do PA to achieve a health benefit" or "the amount of PA everybody needs, to strengthen the heart and lungs" or "sport endurance causing fractures in bones and the body". It highlights the need for more education even for HCPs. Burdick Laura (2015) in a study among HCPs found that more than $95 \%$ of nurse and community healthcare workers needed more information on PA guidelines.

This study also showed that the participants had a positive attitude towards PA. The positive attitudes towards PA are identified in physical, mental and social aspects of health. The majority of the participants strongly believed they are interested in doing daily exercise as PA improves their physical health. It is obvious that individuals care for their health and, therefore, perceiving the benefits of PA can lead to a positive attitude towards it. Poor PA amongst HCPs seems to pose a major threat in their lives, as observed amongst the general population in many studies (French, Story, \& Jeffery, 2001; Hidalgo, 2016). They also had positive attitudes about the effect of PA in promoting social contacts (Bredahl, Christensen et al., 2011; Lindwall \& Jonsdottir, 2013; Walter et al., 2011). HCPs should be role models for maintaining a healthy lifestyle for the general population (Skaal, 2011).

The results of the current study showed that the majority of participants had a good level of PA practice. Maintaining personal good health and healthy functioning for daily activities is critical (Lahti et al., 2010). Therefore, it is important for individuals to ensure that a sufficient intensity of regular physical activity is performed to maintain good health, physical functioning and work activity of a high standard (Lahti et al., 2010). The results showed that the majority of participants sometimes do PA and only $14.3 \%$ always do PA. Most of the 
participants do PA of one to four hours per week and only $4.8 \%$ of them do PA for more than four hours per week. Lindwall et al., (2011) found that healthcare workers follow relatively unfavourable lifestyles and are not involved in healthy lifestyle programmes in their hospitals or their communities (Frank et al., 2008). Considering perceived barriers may help HCPs to promote their PA. According to the participants, the main reasons preventing them from working out were the lack of free time, working hours and also negligence. Also, working in a hospital is usually a physically taxing job and when combined with demanding household chores, it can reduce one's willingness to engage in other PA, which was also supported by other studies (Harenstam, 2005; Stein, 2000).

It was demonstrated in this study that there is a positive relationship between knowledge and attitudes. Similarly, there is a positive relationship between knowledge and practices. This supports a general idea that to promote PA, it is important to enhance individuals' knowledge which can then result in a positive attitude and good practice.

To promote PA, individuals should know about its benefits. A number of health benefits are generally associated with PA. These benefits are evident when an individual adheres to exercise principles such as appropriate frequency, duration and intensity of exercise (Torquati \& Alexande, 2016). Some studies have identified obstacles to exercising for health care professionals including fatigue, lack of time, and family commitments (Siyabonga \& Nomathemba, 2016).

\subsection{Limitations of the Study}

There are some limitations. Although, all the potential participants took part in this study, the sample size was small. This was a cross-sectional study that was conducted in one of the subdivisions in Fiji, therefore the results cannot be generalised to the whole Fijian populations. This study also was a questionnaire-based survey which was heavily dependent on participants' memory and answers provided at the time of filing the questionnaire.

\section{Conclusion}

This study found that HCPs in Fiji had a high level of KAP regarding PA. It also demonstrated that promotion of the levels of knowledge are likely to result in promotion of attitudes and practices. Personal factors such as KAP are not the only factors affecting PA. Considering a setting-based approach and promoting the place where people are working is also important to changing lifestyles. Using different behavioural change models that consider factors such as perceived benefits and perceived barriers, along with subjective norms may work better among HCPs in Fiji as this study highlighted. There is need for HCP to be exposed to more opportunities for engaging in PA which will enrich their knowledge of PA and how to achieve optimal fitness levels. Further studies should be conducted to investigate the reasons for not practicing PA. Health promotion experts and policymakers are invited to use the results of this study to develop tailored interventions and evaluate its influence on PA among HCPs in Fiji.

\section{Acknowledgements}

We are grateful to the medical officer for the Suva subdivision, Dr Swastika S, for her agreement to use the seven healthcare centres in this study. We appreciate Mr. Ricardo Morris for editing this paper. We also acknowledge all HCPs who participated in this study.

\section{Competing Interests Statement}

The authors declare that there are no competing or potential conflicts of interest.

\section{References}

Adeniyi, A. F., Idowu, O. A., Ogwumike, O. O., \& Adeniyi, C. Y. (2012). Comparative influence of self-efficacy, social support and perceiived barriers on low physical activity development in patients with type 2 diabetes, hypertension or stroke. Ethiopian journal of health sciences, 22(2).

Ainsworth, B. E., Haskell, W. L., Whitt, M. C., Irwin, M. L., Swartz, A. M., Strath, S. J., ... \& Leon, A. S. (2000). Compendium of physical activities: an update of activity codes and MET intensities. Medicine and science in sports and exercise, 32(9; SUPP/1), S498-S504. https://doi.org/10.1097/00005768-200009001-00009

Andersen, L. B., Schnohr, P., Schroll, M., \& Hein, H. O. (2000). All-cause mortality associated with physical activity during leisure time, work, sports, and cycling to work. Archives of internal medicine, 160(11), 1621-1628. https://doi.org/10.1001/archinte.160.11.1621

Arem, H., Moore, S. C., Patel, A., Hartge, P., De Gonzalez, A. B., Visvanathan, K., ... \& Matthews, C. E. (2015). Leisure time physical activity and mortality: a detailed pooled analysis of the dose-response relationship. JAMA internal medicine, 175(6), 959-967. https://doi.org/10.1001/jamainternmed.2015.0533

Azar, D., Naughton, G. A., \& Joseph, C. W. (2009). Physical activity and social connectedness in single-parent 
families. Leisure Studies, 28(3), 349-358. https://doi.org/10.1080/02614360903046656

Bailey, R. (2005). Evaluating the relationship between physical education, sport and social inclusion. Educational review, 57(1), 71-90. https://doi.org/10.1080/0013191042000274196

Bauman, A. E., Reis, R. S., Sallis, J. F., Wells, J. C., Loos, R. J., Martin, B. W., \& Lancet Physical Activity Series Working Group. (2012). Correlates of physical activity: why are some people physically active and others not?. The lancet, 380(9838), 258-271. https://doi.org/10.1016/S0140-6736(12)60735-1

Biswas, A., Oh, P. I., Faulkner, G. E., Bajaj, R. R., Silver, M. A., Mitchell, M. S., \& Alter, D. A. (2015). Sedentary time and its association with risk for disease incidence, mortality, and hospitalization in adults: a systematic review and meta-analysis. Annals of internal medicine, 162(2), 123-132. https://doi.org/10.7326/M14-1651

Bock, C., Diehm, C., \& Schneider, S. (2012). Physical activity promotion in primary health care: results from a German physician survey. The European journal of general practice, 18(2), 86-91. https://doi.org/10.3109/13814788.2012.675504

Bolarinde, S. O., Olagbegi, O., Ebenezer, D., \& Akinrinbola, B. (2015). knowledge, attitude and practice of physical activity among health professionals in a Nigerian tertiary health institution. South American Journal of Public Health.

Bolarinde, S. O., Olagbegi, O., Ebenezer, D., \& Akinrinbola, B. (2015). knowledge, attitude and practice of physical activity among health professionals in a Nigerian tertiary health institution. South American Journal of Public Health, 3(2). 1-10.

Boulé, N. G., Haddad, E., Kenny, G. P., Wells, G. A., \& Sigal, R. J. (2001). Effects of exercise on glycemic control and body mass in type 2 diabetes mellitus: a meta-analysis of controlled clinical trials. Jama, 286(10), 1218-1227. https://doi.org/10.1001/jama.286.10.1218

Bredahl, T. V. G., Christensen, R. S., Justesen, J. B., \& Christensen, J. R. (2019). Adherence to physical activity in a workplace setting-A qualitative interview study. Cogent Medicine, 6(1), 1581446. https://doi.org/10.1080/2331205X.2019.1581446

Burdick, L., Mielke, G. I., Parra, D. C., Gomes, G., Florindo, A., Bracco, M., ... \& Hallal, P. C. (2015). Physicians', nurses' and community health workers' knowledge about physical activity in Brazil: A cross-sectional study. Preventive medicine reports, 2, 467-472. https://doi.org/10.1016/j.pmedr.2015.06.001

Burgoyne, L. N., Woods, C., Coleman, R., \& Perry, I. J. (2008). Neighbourhood perceptions of physical activity: a qualitative study. BMC Public Health, 8(1), 1-9. https://doi.org/10.1186/1471-2458-8-101

Carter, K., Cornelius, M., Taylor, R., Ali, S. S., Rao, C., Lopez, A. D., ... \& Mowry, C. (2011). Mortality trends in Fiji. Australian and New Zealand journal of public health, 35(5), 412-420. https://doi.org/10.1111/j.1753-6405.2011.00740.x

Caspersen, C. J., Powell, K. E., \& Christenson, G. M. (1985). Physical activity, exercise, and physical fitness: definitions and distinctions for health-related research. Public health reports, 100(2), 126.

Craig, C. L., Marshall, A. L., Sjöström, M., Bauman, A. E., Booth, M. L., Ainsworth, B. E., ... \& Oja, P. (2003). International physical activity questionnaire: 12-country reliability and validity. Medicine \& science in sports \& exercise, 35(8), 1381-1395. https://doi.org/10.1249/01.MSS.0000078924.61453.FB

Deliens, T., Deforche, B., De Bourdeaudhuij, I., \& Clarys, P. (2015). Determinants of physical activity and sedentary behaviour in university students: a qualitative study using focus group discussions. BMC public health, 15(1), 1-9. https://doi.org/10.1186/s12889-015-1553-4

Dikareva, A., Harvey, W. J., Cicchillitti, M. A., Bartlett, S. J., \& Andersen, R. E. (2016). Exploring perceptions of barriers, facilitators, and motivators to physical activity among female bariatric patients: implications for physical activity programming. American Journal of Health Promotion, 30(7), 536-544. https://doi.org/10.4278/ajhp.140609-QUAL-270

Frank, E., Tong, E., Lobelo, F., Carrera, J., \& Duperly, J. (2008). Physical activity levels and counseling practices of US medical students. Medicine and science in sports and exercise, 40(3), 413-421. https://doi.org/10.1249/MSS.0b013e31815ff399

French, S. A., Story, M., \& Jeffery, R. W. (2001). Environmental influences on eating and physical activity. Annual review of public health, 22(1), 309-335. Retrieved from https://doi.org/10.1146/annurev.publhealth.22.1.309

French, S. A., Story, M., \& Jeffery, R. W. (2001). Environmental influences on eating and physical activity. Annual 
review of public health, 22(1), 309-335. https://doi.org/10.1123/jpah.7.5.571

Gill, J. M., \& Malkova, D. (2006). Physical activity, fitness and cardiovascular disease risk in adults: interactions with insulin resistance and obesity. Clinical science, 110(4), 409-425. https://doi.org/10.1042/CS20050207

Härenstam, A., \& MOA Research Group. (2005). Different development trends in working life and increasing occupational stress require new work environment strategies. Work, 24(3), 261-277.

Hébert, E. T., Caughy, M. O., \& Shuval, K. (2012). Primary care providers' perceptions of physical activity counselling in a clinical setting: a systematic review. British journal of sports medicine, 46(9), 625-631. https://doi.org/10.1136/bjsports-2011-090734

Hidalgo, K. D., Mielke, G. I., Parra, D. C., Lobelo, F., Simões, E. J., Gomes, G. O., ... \& Hallal, P. C. (2016). Health promoting practices and personal lifestyle behaviors of Brazilian health professionals. BMC Public Health, 16(1), 1-10. https://doi.org/10.1186/s12889-016-3778-2

Hull, E. E., Rofey, D. L., Robertson, R. J., Nagle, E. F., Otto, A. D., \& Aaron, D. J. (2010). Influence of marriage and parenthood on physical activity: a 2-year prospective analysis. Journal of Physical Activity and Health, 7(5), 577-583. https://doi.org/10.1123/jpah.7.5.577

Iwuala, S. O., Sekoni, A. O., Olamoyegun, M. A., Akanbi, M. A., Sabir, A. A., \& Ayankogbe, O. O. (2015). Self-Reported Physical Activity among Health Care Professionals in South-West Nigeria. Nigerian journal of clinical practice, 18(6), 790-795. https://doi.org/10.4103/1119-3077.163275

Jamil, A. T., Ismail, A., Idris, I. B., Soo, K. C., Teng, A. J., Bahaman, N. A., \& Fadzil, M. F. (2016). Levels of physical activity and its associated factors among health care workers. Malaysian J Public Health Med, 16(3), $127-33$.

Johansson, L. M., Lingfors, H., Golsäter, M., Kristenson, M., \& Fransson, E. I. (2019). Can physical activity compensate for low socioeconomic status with regard to poor self-rated health and low quality-of-life? Health and quality of life outcomes, 17(1), 1-10. https://doi.org/10.1186/s12955-019-1102-4

Kesaniemi, Y. A., Danforth, E., Jensen, M. D., Kopelman, P. G., Lefèbvre, P. I. E. R. R. E., \& Reeder, B. A. (2001). Dose-response issues concerning physical activity and health: an evidence-based symposium. Medicine \& Science in Sports \& Exercise, 33(6), S351-S358. https://doi.org/10.1097/00005768-200106001-00003

Kolbe-Alexander, T. L., Pacheco, K., Tomaz, S. A., Karpul, D., \& Lambert, E. V. (2015). The relationship between the built environment and habitual levels of physical activity in South African older adults: a pilot study. BMC public health, 15(1), 1-9. https://doi.org/10.1186/s12889-015-1853-8

Korn, L., Gonen, E., Shaked, Y., \& Golan, M. (2013). Health perceptions, self and body image, physical activity and nutrition among undergraduate students in Israel. PloS one, 8(3), e58543. https://doi.org/10.1371/journal.pone.0058543

Kunene, S. H., \& Taukobong, N. P. (2015). Level of physical activity of health professionals in a district hospital in KwaZulu-Natal, South Africa. The South African journal of physiotherapy, 71(1). https://doi.org/10.4102/sajp.v71i1.234

Lahti, J., Laaksonen, M., Lahelma, E., \& Rahkonen, O. (2010). The impact of physical activity on sickness absence. Scandinavian journal of medicine \& science in sports, 20(2), 191-199. https://doi.org/10.1111/j.1600-0838.2009.00886.x

Lindwall, M., Gerber, M., Jonsdottir, I. H., Börjesson, M., \& Ahlborg Jr, G. (2014). The relationships of change in physical activity with change in depression, anxiety, and burnout: A longitudinal study of Swedish healthcare workers. Health Psychology, 33(11), 1309. https://doi.org/10.1037/a0034402

Memon, M. S., Shaikh, S. A., Shaikh, A. R., Fahim, M. F., Mumtaz, S. N., \& Ahmed, N. (2015). An assessment of knowledge, attitude and practices (KAP) towards diabetes and diabetic retinopathy in a suburban town of Karachi. Pakistan journal of medical sciences, 31(1), 183. https://doi.org/10.12669/pjms.311.6317

Motl, R. W., \& McAuley, E. (2010). Physical activity, disability, and quality of life in older adults. Physical Medicine and Rehabilitation Clinics, 21(2), 299-308. https://doi.org/10.1016/j.pmr.2009.12.006

Moustafa, S., Tawbe, Z., Sleiman, F., Daouk, S. E., Al-Iskandarani, M., Sleiman, M., \& Hoteit, M. (2017). Body image perception in association with healthy lifestyle behaviour's in Lebanese men and women. International Journal of School and Cognitive Psychology, 4(4), 2-7. https://doi.org/10.4172/2469-9837.1000201

Pratt, M., Macera, C. A., Sallis, J. F., O'Donnell, M., \& Frank, L. D. (2004). Economic interventions to promote 
physical activity: application of the SLOTH model. American journal of preventive medicine, 27(3), 136-145. https://doi.org/10.1016/j.amepre.2004.06.015

Ribera, A. P., McKenna, J., \& Riddoch, C. (2005). Attitudes and practices of physicians and nurses regarding physical activity promotion in the Catalan primary health-care system. The European Journal of Public Health, 15(6), 569-575. https://doi.org/10.1093/eurpub/cki045

Rosenberg, L., Kipping-Ruane, K. L., Boggs, D. A., \& Palmer, J. R. (2013). Physical activity and the incidence of obesity in young African-American women. American journal of preventive medicine, 45(3), 262-268. https://doi.org/10.1016/j.amepre.2013.04.016

Sigal, R. J., Kenny, G. P., Wasserman, D. H., Castaneda-Sceppa, C., \& White, R. D. (2006). Physical activity/exercise and type 2 diabetes: a consensus statement from the American Diabetes Association. Diabetes care, 29(6), 1433-1438. https://doi.org/10.2337/dc06-9910

Skaal, L., \& Pengpid, S. (2011). Physical activity, fitness level and health problems of healthcare workers in South Africa: the transtheoretical model as an explanatory framework: physical activity and fitness. African Journal for Physical Health Education, Recreation and Dance, 17(si-1), 612-623.

Torquati, L., Pavey, T., Kolbe-Alexander, T., \& Leveritt, M. (2017). Promoting diet and physical activity in nurses: a systematic review. American Journal of Health Promotion, 31(1), 19-27. https://doi.org/10.4278/ajhp.141107-LIT-562

Vandelanotte, C., Short, C., Rockloff, M., Di Millia, L., Ronan, K., Happell, B., \& Duncan, M. J. (2015). How do different occupational factors influence total, occupational, and leisure-time physical activity?. Journal of Physical Activity and Health, 12(2), 200-207. https://doi.org/10.1123/jpah.2013-0098

Walter, C. M., Du Randt, R., \& Venter, D. J. (2011). The physical activity and health status of two generations of Black South African professional women. Health SA Gesondheid, 16(1). https://doi.org/10.4102/hsag.v16i1.538

Westerterp, K. R. (2013). Physical activity and physical activity induced energy expenditure in humans: measurement, determinants, and effects. Frontiers in physiology, 4, 90. https://doi.org/10.3389/fphys.2013.00090

Wilcox, S., Castro, C., King, A. C., Housemann, R., \& Brownson, R. C. (2000). Determinants of leisure time physical activity in rural compared with urban older and ethnically diverse women in the United States. Journal of Epidemiology \& Community Health, 54(9), 667-672. https://doi.org/10.1136/jech.54.9.667

Williams, S. L., \& French, D. P. (2011). What are the most effective intervention techniques for changing physical activity self-efficacy and physical activity behaviour-and are they the same?. Health education research, 26(2), 308-322. https://doi.org/10.1093/her/cyr005

Wilmot, E. G., Edwardson, C. L., Achana, F. A., Davies, M. J., Gorely, T., Gray, L. J., ... \& Biddle, S. J. (2012). Sedentary time in adults and the association with diabetes, cardiovascular disease and death: systematic review and meta-analysis. Diabetologia, 55(11), 2895-2905. https://doi.org/10.1007/s00125-012-2677-z

Wilson, D. M., Ciliska, D., Singer, J., Williams, K., Alleyne, J., \& Lindsay, E. (1992). Family Physicians and Exercise Counseling: Can they be influenced to provide more?. Canadian Family Physician, 38, 2003.

Woolf, A. D., Erwin, J., \& March, L. (2012). The need to address the burden of musculoskeletal conditions. Best practice \& research Clinical rheumatology, 26(2), 183-224.https://doi.org/10.1016/j.berh.2012.03.005

World Health Organization. (2010). Global recommendations on physical activity for health; 2010. Retrieved from https://www.who.int/publications/i/item/9789241599979

\section{Copyrights}

Copyright for this article is retained by the author(s), with first publication rights granted to the journal.

This is an open-access article distributed under the terms and conditions of the Creative Commons Attribution license (http://creativecommons.org/licenses/by/4.0/). 